\title{
Editorial: The Archbishop and the Law
}

The Archbishop of Canterbury caused a stir recently by inviting his audience to consider the extent to which people with strong beliefs and codes of their own, separate from the prevailing ethos of the state, should be accommodated within the law of a modern democracy. Perhaps unwisely (or perhaps cleverly if he wanted to get publicity for his thoughts) he mentioned within this context the two million or so people in Britain who have allegiance of some sort to the Sharia.

The outcry was predictable. Dr Williams was immediately condemned by all three major party political leaders and by the vast majority of commentators. This alone may have tempted some to think that there must be something to be said for the Archbishop's views. This temptation was not decreased when some, shown that they may have misinterpreted what the Archbishop actually said, complained that his speech was very dense. The Archbishop is doubtless too charitable a man to wonder where the denseness really lay, but it is clearly a sign of the times when one is not allowed to present a complicated argument in public, lest politicians and journalists find it too hard to understand. The impression that the Archbishop was being traduced was not lessened when it emerged that the British state has already made regulatory accommodations for Muslim practice in a couple of crucial areas, including marriage, though this fact was apparently not known to most of those who rushed to condemn.

It is unlikely that Dr Williams was actually advocating two legal jurisdictions within a unitary system. But if he meant that law frequently changes to accommodate the practices of those who are bound by it, even in order to reduce friction between the state and groups of citizens, what he said should be too obvious to need pointing out.

However it seems there was another point underlying the speech. It concerns the way the sensibilities of religious and other conscientious minorities should or should not be accommodated within systems of law increasingly driven by the precepts of secular humanism, such as is the case in Britain and the European Union. As we see with legislation over abortion, infertility treatment and homosexual rights this question has a far wider significance than the impact 


\section{Editorial}

of Sharia Law in Britain, affecting as it does the rights of doctors and nurses in state run health services and the ability of adoption agencies to chose prospective parents for the children in their care. Clashes of these sorts are not likely to decrease, which is something philosophers, following the Archbishop's lead, might give some thought to. 